\title{
Metallurgical Amenability Testing of Bir-Tawilah Gold Deposit in Central Arabian Gold Region, Saudi Arabia
}

\author{
Dr. Gamal Saad Abelhaffez
}

Mining \& metallurgical Engineering Dept., Faculty of Engineering, Assiut University, Egypt

gamalhaffez@yahoo.com

\begin{abstract}
This paper evaluates the amenability of free milling gold for one of the proposed Saudi Arabia gold deposits. The metallurgical treatments include the gravity recoverable gold (GRG) followed by intensive cyanidation. Composites of high grade ore $(>1 \mathrm{~g} / \mathrm{t})$ have been used as a feed for the cyanide leaching tests. Benchmark of GRG amenability tests followed by Falcon centrifuge gravity separation have been carried out on different feed samples to produce different gold concentrates and tails. The concentrates and tails from different GRG stages were leached using high cyanide concentrations (up to $20 \mathrm{~g} / \mathrm{L}$ ). The results show that $50.7 \%$ of gold contained in high-grade ore deposit is amenable for gravity recovery. The results also prove the amenability of Bir-Tawellah for gravity separation with high gold recovery exceeding $85 \%$. The cyanidation leaching of different concentrates showed that gold recovery $>96 \%$ can be achieved indicated a free milling prospective of the Bir-Taweelah deposit. The present study shows that the deposit of Bir-Tawellah is ranked as free milling with no gold Telluride present. The gravity recovery of gold using Falcon concentrate ore shows high gold recovery (up to $70 \%$ ) and the gold recovery depends on the sample size fractions.
\end{abstract}

\section{INTRODUCTION}

There are different metallurgical classifications of gold bearing ores. Depending on what type of ore is present, a suitable gold recovery process should be designated to deal with the recovery challenges for each ore type. Typical gold bearing ores includes: alluvial, oxidizes, free milling, preg-robbing and complex and refractory ores. Gold in alluvial, oxides are easy to recover by gravity or cyanide leaching [1]. The free milling deposits contain gold that are readily amenable to cyanidation with little or no preparations beforehand. The benchmark of free milling is a gold recovery $>95 \%$ in $24 \mathrm{hrs}$ at grind of $80 \%$ passing 75 micron. The actual recovery of free-milling ore might be less due to economics dictates coarse grinding [2]. Witwaterland (South Africa), Jacobina (Brazil) and Tarkwa (Ghana) are examples of free milling placers deposits [3,4]). For refractory ores the gold in intimately associated with the sulphides minerals especially pyrite and arsenopyrite. Gold can also be locked in the sulphide solution matrix. Giant Yellowknife, Campbell mine (Canada), Sao Bento (Brazil) and Carline deposits are all examples of refractory gold deposits [5]. In either case, the gold is not accessible to cyanidation and the removal and/or destruction of the refractory material has to be carried out before leaching in order to get a reasonable gold recovery.

Gravity separation is the most well-known and accepted technique of pre-concentration and it has been used as a primary application of mineral concentration for centuries. Due to its high efficiency and low cost, gravity separation is always the first consideration in any flowsheet development program and always features in any flowsheet where there is sufficient differences between the specific gravity of the valuable and gangue minerals. In the case of gold, gravity separation can quickly generate a precious metal concentrate that can be sold direct to refineries, resulting in better payment terms, faster payback and immediate cash-flows[6].

The small footprint of the gravity plants means less capital outlay and better security for these small volume high-values concentrates. In general, gravity separation in gold processing contributes to reject barren waste as an initial pre-concentration step, recover malleable and/or friable coarse gold, clean low weight yield bulk concentrates and finally generate a precious metal concentrate that can go direct to a refinery rather than a smelter. Typical equipment used in gravity separation include: Knelson and Falcon Superbowl centrifugal, Holman, Denver, Deister, Wilfley, Mozley, Gemini tables, Humphreys, Vickers, Reichert, Carpco, and Mineral Technologies, single and double spiral, 


\section{Dr. Gamal Saad Abelhaffez}

Reichert \& various trays and sluices and finally Bateman 1 tonne/hr and 15 tons $/ \mathrm{hr}$ dense media separation plant [2].

Cyanidation is the process of oxidizing gold in an alkaline cyanide solution to form a highly soluble aurocyanide complex $\left(\mathrm{AuCN}_{2}\right)$ that can be adsorbed on activated carbon from the leach solution. A typical lixiviant used in cyanidation is sodium cyanide $(\mathrm{NaCN})$, best operated at $\mathrm{pH} 9.9-11.5$ [6]. The cyanidation of gold ores was patented in U.K. in 1887 and piloted in 1888 in Australia and used commercially at the Crown Mine in New Zealand [7].

Hydrothermal ore paragenesis represents $>90 \%$ of total ores in the Bi'r Tawilah mineralized samples and they are arranged chronologically from oldest to youngest as follows: rutile, sphalerite, chalcopyrite, pyrite (with visible gold inclusions) and arsenopyrite. Gold is either native or electrum with up to 27.19 weight percent Ag. Due to weathering, some supergene ore minerals are formed (ferric Ca-arsenate and ferric oxyhydroxide) [8]. Free gold is present as inclusions either in interstitial quartz that fills voids or in fresh and altered pyrite. It is interesting to distinguish gold inclusions in pyrite as "visible and invisible" gold where the visible one is only encountered in the deep fresh horizon whereas invisible gold in the pyrite lattice is liberated and becomes visible due to supergene alteration of pyrite during weathering [9-11].

Despite 100 over years of research and development with activated carbon, there is still not a complete understanding of the gold adsorption and desorption mechanism. Majority of the modeling work carried out for gold processing are empirical in nature. Limited studies on Computational fluid dynamics (CFD) modeling of extraction and recovery processes have been carried out on other mineral ores, the CFD prediction were found to be in a good agreement with experimental data. In future work CFD modeling will be expanded to include other phenomenon associated with mineral extraction leaching, leading to the full of an operating heap[12,13].

In this process the ore is grinded to a suitable degree of liberation, and then poured into a tank along with lixiviate and agitated for a long residence time up to $72 \mathrm{hrs}$. In Merrill Crowe process, zinc dust is normally added to clarified and de-oxygenated solution in order to precipitate gold out of solution and recover it to transform into bullion. In the seventies and eighties, discoveries in applications of activated carbon spurred the development of the carbon-in-pulp (CIP) and carbon-in-leach (CIL) processes, which introduced carbon as more effective method of gold recovery from solutions than Merrill-Crowe.

\section{EXPERIMENTAL}

\subsection{Sample Preparation}

The gold samples from Ma'aden Gold Company were received in a form of half and quarter cores. The received samples were approximately $114 \mathrm{~kg}$ and categorized as Hi-Grade representation for BirTawellah [14]. Each batch sample was crushed and mixed to form a composite. Each composite was crushed to minus $19 \mathrm{~mm}$. Each crushed composite was homogenized and a sub-sample extracted by cone and quartering methods in preparation testing schedule. The particle size distribution "PSD" and gold and silver interval grades of the crushed samples (screen metallic, fire assay and ICP-MS for chemical analysis) are presented in Table 1. From the ICP-MS analysis, it was found that low concentrations of tellurium in all the tested samples suggesting that there is probably not a significant amount of gold present as Tellurides.

Table1. Bir-Tawilla High grade composites PSD and interval Au and Ag grades analysis

\begin{tabular}{|c|c|c|c|c|c|c|c|}
\hline \multicolumn{2}{|c|}{ size } & \multicolumn{2}{c|}{ Weight } & \multicolumn{2}{c|}{ Au } & \multicolumn{2}{c|}{ Ag } \\
\hline $\begin{array}{c}\text { Taylor } \\
\text { mesh }\end{array}$ & Micron & g & Cum \% & g/t & Cum \% & g/t & Cum \% \\
\hline 8 & 2.360 & 0 & 100 & & 100 & & 100 \\
\hline 12 & 1.700 & 194.6 & 82.55 & 14.29 & 61 & 5.8 & 75.3 \\
\hline 16 & 1.180 & 170.1 & 67.29 & 4.61 & 50 & 1.3 & 70.5 \\
\hline 20 & 850 & 91.4 & 59.09 & 1.58 & 48 & 1.4 & 67.7 \\
\hline 30 & 600 & 79.8 & 51.93 & 1.75 & 46 & 4.3 & 60.2 \\
\hline 40 & 425 & 68.5 & 45.79 & 3.42 & 42.7 & 2 & 57.2 \\
\hline 50 & 300 & 69.2 & 39.58 & 7.75 & 35.2 & 3.6 & 51.7 \\
\hline 70 & 212 & 50.4 & 35.06 & 6.04 & 30.9 & 3.8 & 47.5 \\
\hline 100 & 150 & 52 & 30.4 & 6.72 & 26 & 3 & 44.1 \\
\hline 140 & 106 & 40.4 & 26.78 & 8.01 & 21.5 & 5.1 & 39.6 \\
\hline 200 & 75 & 45.3 & 22.72 & 6.68 & 17.3 & 8.4 & 31.3 \\
\hline 270 & 53 & 0.7 & 22.66 & 6.10 & 17.2 & 4.3 & 31.2 \\
\hline 400 & 37 & 74.7 & 15.96 & 5.52 & 11.4 & 4.2 & 24.3 \\
\hline-400 & -37 & 177.9 & 0 & 4.56 & 0 & 6.2 & 0 \\
\hline
\end{tabular}



Arabia

The gold and silver head grades of the composite are $6.15 \mathrm{~g} / \mathrm{t}$ and $2.3 \mathrm{~g} / \mathrm{t}$ respectively. These head grades were averaged from multiple assays and tests. The presence of a "nuggets effect" likely contributed to variability in the gold assays, particularly in the high-grade sample.

\subsection{Lab Testing Schedule}

Two tests spectrums were conducted on the composite samples, namely; benchmark GRG and intensive cyanide leaching.

\subsubsection{Benchmark GRG}

Gravity recoverable gold is defined as gold in particles whose gold content is high enough to make them sufficiently distinct from other particles present as to be recovered selectively by gravity methods in small mass "pull" yield.

The McGill standard GRG test [14] is an ore characterization test using three stages of sequential liberation and recovery with Knelson KC-MD3 centrifuge to determine the size distribution of GRG. Figure 1 shows the schematic flowsheet for the GRG of Bir- Tawellah ore using Falcon concentrator. The test results are summarized in Table 2 [14].

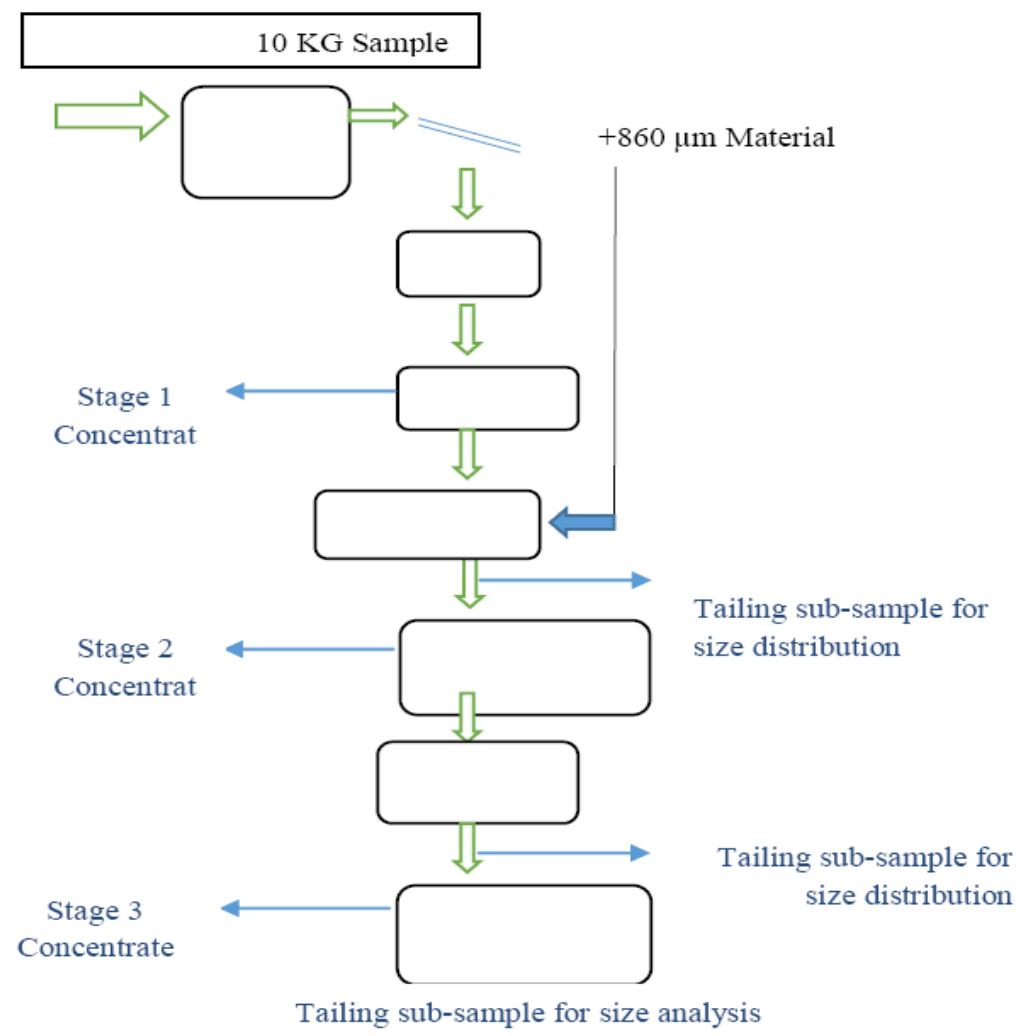

Figure1. Standard GRG test at Bir Tawellah [7]

Table2. Results of standard GRG test for High grade composite at Bir-Tawellah

\begin{tabular}{|c|c|c|c|c|c|c|c|c|c|c|c|}
\hline \multicolumn{7}{|c|}{ Sieve Size } & \multicolumn{6}{c|}{ Stage 1 - Concentrate } & \multicolumn{5}{c|}{ Stage 2 - Concentrate } \\
\hline $\begin{array}{c}\text { Tyler } \\
\text { Mesh }\end{array}$ & Microns & $(\mathrm{g})$ & Weight (\%) & Au (g/t) & Dist. \% & Fract'n (\%) & $(\mathrm{g})$ & Weight (\%) & Au (g/t) & Dist. \% & Fract'n (\%) \\
\hline 20 & 850 & & & & & & & & & & \\
\hline 30 & 600 & 6.5 & 5.6 & 8.26 & $0.55 \%$ & 0.09 & & & & & \\
\hline 40 & 425 & 15.3 & 13.3 & 145.46 & $22.92 \%$ & 3.63 & 4 & 3.5 & 350 & 11.5 & 2.3 \\
\hline 50 & 300 & 17.2 & 14.9 & 41.81 & $7.41 \%$ & 1.17 & 22 & 19.1 & 135.2 & 24.4 & 4.9 \\
\hline 70 & 212 & 13.6 & 11.8 & 46.17 & $6.47 \%$ & 1 & 27.1 & 23.5 & 55.44 & 1.3 & 2.5 \\
\hline 100 & 150 & 11.3 & 9.8 & 46.3 & $5.39 \%$ & 0.9 & 17.4 & 15.1 & 49.27 & 7 & 1.4 \\
\hline 140 & 106 & 9.5 & 8.3 & 56.36 & $5.51 \%$ & 0.9 & 10 & 8.7 & 81.52 & 6.7 & 1.3 \\
\hline 200 & 75 & 9.8 & 8.5 & 76.93 & $7.76 \%$ & 1.2 & 8 & 6.9 & 92.26 & 6 & 1.2 \\
\hline 270 & 53 & 8.5 & 7.4 & 94.78 & $8.30 \%$ & 1.3 & 6 & 5.2 & 102.41 & 5 & 1 \\
\hline 400 & 37 & 8.8 & 7.6 & 87.08 & $7.89 \%$ & 1.3 & 6 & 5.2 & 124.88 & 6.1 & 1.2 \\
\hline-400 & -37 & 14.6 & 12.7 & 184.93 & $27.80 \%$ & 4.4 & 14.9 & 12.9 & 171.58 & 20.9 & 4.2 \\
\hline & TOTAL & 115.1 & 100 & 84.37 & $100.00 \%$ & 15.8 & 115.4 & 100 & 105.79 & 100 & 19.9 \\
\hline
\end{tabular}




\begin{tabular}{|c|c|c|c|c|c|c|c|c|c|c|c|}
\hline \hline \multicolumn{7}{|c|}{ Sieve Size } & \multicolumn{7}{|c|}{ Stage 3 - Concentrate } & \multicolumn{5}{c|}{ Final Tailings (normalized weight) } \\
\hline $\begin{array}{c}\text { Tyler } \\
\text { Mesh }\end{array}$ & Microns & $(\mathrm{g})$ & Weight (\%) & Au (g/t) & Dist. \% & Fract'n $(\%)$ & $(\mathrm{g})$ & Weight $(\%)$ & Au $(\mathrm{g} / \mathrm{t})$ & Dist. \% & Fract'n $(\%)$ \\
\hline 20 & 850 & 0 & 0 & 0 & 0 & 0 & 0 & 0 & 0 & 0 & 0 \\
\hline 30 & 600 & 0 & 0 & 0 & 0 & 0 & 0 & 0 & 0 & 0 & 0 \\
\hline 40 & 425 & 0 & 0 & 0 & 0 & 0 & 0 & 0 & 0 & 0 & 0 \\
\hline 50 & 300 & 0 & 0 & 0 & 0 & 0 & 0 & 0 & 0 & 0 & 0 \\
\hline 70 & 212 & 7.4 & 7.4 & 73.34 & 5.9 & 0.89 & 0 & 0 & 0 & 0 & 0 \\
\hline 100 & 150 & 6.4 & 6.4 & 53.98 & 3.8 & 0.56 & 541.5 & 5.6 & 3.43 & 6 & 3 \\
\hline 140 & 106 & 15.3 & 15.3 & 68.44 & 11.4 & 1.7 & $1,273.30$ & 13.2 & 2.3 & 9.2 & 4.8 \\
\hline 200 & 75 & 16.6 & 16.6 & 81.06 & 14.7 & 2.2 & $1,509.90$ & 15.7 & 3.56 & 17.9 & 8.8 \\
\hline 270 & 53 & 23.4 & 23.3 & 91.88 & 23.4 & 3.5 & 833.5 & 8.7 & 3.79 & 9.5 & 5.2 \\
\hline 400 & 37 & 5.4 & 5.4 & 65.7 & 3.9 & 0.6 & $1,752.00$ & 18.2 & 4.21 & 25.5 & 12 \\
\hline-400 & -37 & 25.8 & 25.7 & 131.58 & 37 & 5.5 & $3,723.90$ & 38.7 & 2.55 & 31.9 & 15.5 \\
\hline
\end{tabular}

The results shown in Table 3 indicate that the tail grade of the GRG standard test is $3.13 \mathrm{~g} / \mathrm{t} \mathrm{Au}$ generated from a feed of $6.12 \mathrm{~g} / \mathrm{t}$ Au. This result mean that almost $50.7 \%$ of gold contained in high grade batch is amenable for gravity recovery.

Table3. Gold distribution in concentrates and tails from GRG test

\begin{tabular}{|c|l|c|c|c|c|}
\hline \multirow{2}{*}{ Grind Size } & \multirow{2}{*}{ Product } & \multicolumn{2}{|c|}{ Weight } & \multicolumn{2}{c|}{ Au } \\
\cline { 3 - 6 }$(\mathrm{P} 80$ in $\mu \mathrm{m})$ & & $\mathbf{( g )}$ & $\mathbf{( \% )}$ & $\mathbf{g} / \mathbf{t}$ & Dist'n (\%) \\
\hline 1773 & Stage 1 Concentrate & 115.1 & 1.16 & 84.37 & 15.8 \\
\hline 278 & Stage 2 Concentrate & 115.4 & 1.16 & 105.79 & 19.9 \\
\hline & & $\mathbf{2 3 0 . 5}$ & $\mathbf{2 . 3 1}$ & $\mathbf{9 5 . 0 9}$ & $\mathbf{3 5 . 8}$ \\
\hline 113 & Stage 1+2 & 100.3 & 1.01 & 91.53 & 15 \\
\hline & Stage 3 Concentrate & $\mathbf{3 3 0 . 8}$ & $\mathbf{3 . 3 2}$ & $\mathbf{9 4 . 0 1}$ & $\mathbf{5 0 . 7}$ \\
\hline 113 & Total Concentrate & $9,634.20$ & 96.68 & 3.13 & 49.3 \\
\hline Calculated & & $\mathbf{9 . 9 6 5 . 0 0}$ & $\mathbf{1 0 0}$ & $\mathbf{6 . 1 5}$ & \\
\hline Average & & & & $\mathbf{6 . 1 5}$ & \\
\hline
\end{tabular}

The tailings as indicated at Table 2 contain considerable amount of gold (50\%) therefore it is expected that the GRG process must be followed by floatation or leaching to extract the remaining gold from GRG tails.

\section{Falcon high mass yield "HMY" test}

In addition to the described standard GRG, two other terms generated to help describe the other types of gold bearing particles recovered or rejected by Knelson centrifuge standard test namely non-GRG and marginal GRG. These two types of particle spectrum is bearing gold but with the gravitational force $(\mathrm{G})$ force of standard test they are sent to tailings. To recover these particles the Falcon centrifuge is used at higher $\mathrm{G}$ forces and produce increased the mass pull. Bir-Tawillah high grade composite was examined in series of Falcon runs at higher G-force up to $150 \mathrm{G}$ compared typical 60 $\mathrm{G}$ of standard test. The flow sheet of this test is shown in Figure 2 [14].

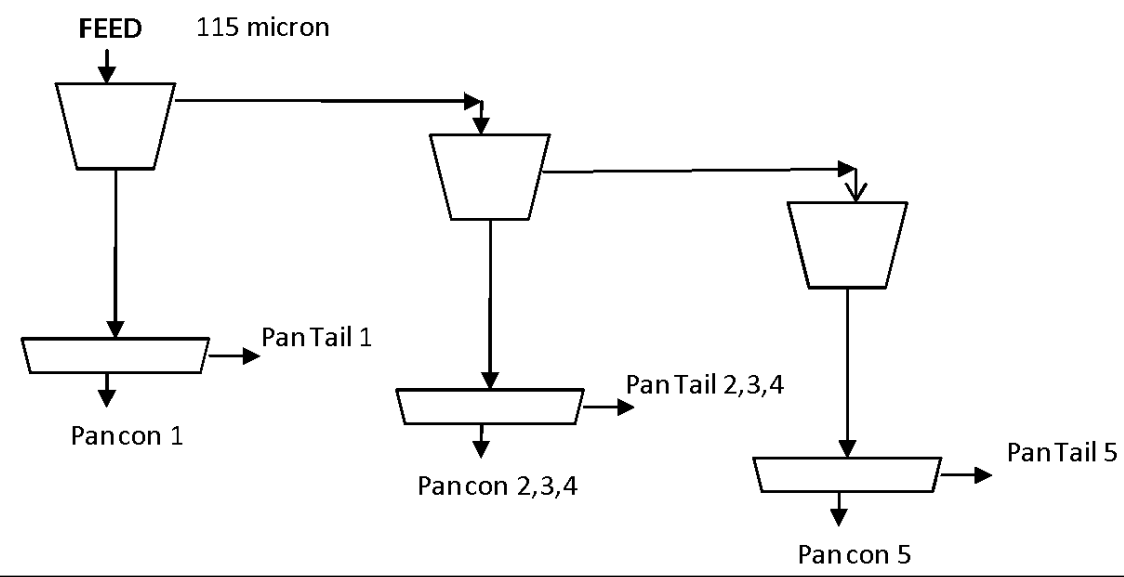

Test Parameters: Pulp Den:15\% - Bowl: 1/32 hole - Pres 3 psi - G-Force 150 G - Speed $55.3 \mathrm{~Hz}$

Figure2. The flowsheet of Falcon centrfuge for Bir-Tawellah [14] 

Arabia

Table 4 indicate a significant increase in gravity recovery, up to $\sim 70 \%$ overall of gold recovery was achieved in the high mass yield (HMY) tests; however, significant gold remains in the tails indicating that an additional cyanide leaching step or pre-concertation by flotation followed by cyanidation would likely be required to recover the remaining gold.

Table4. Results of Falcon centrifuge for Bir-Tawellah test

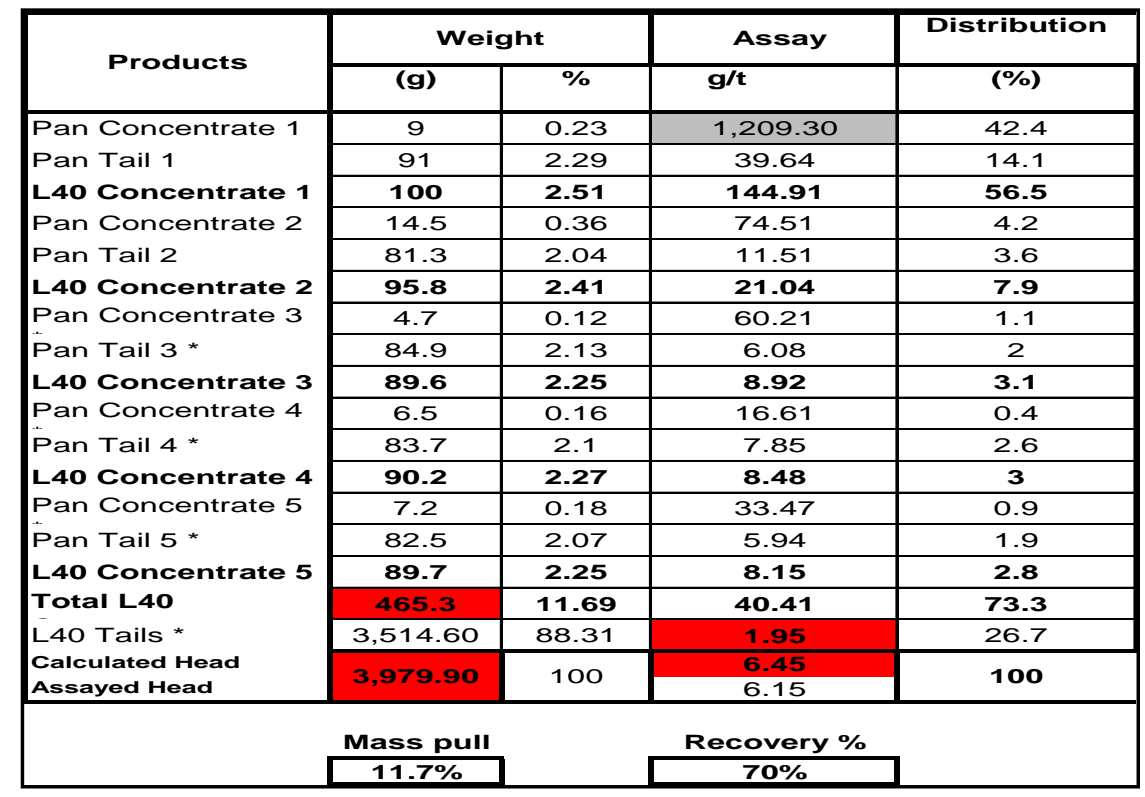

\subsection{2. $C N$ and $C N$ intense test Intensive cyanide leaching}

The products of the Falcon tests were collected to produce feed for the cyanidation tests. The products were assayed so a simple gravity mass balance can be conducted for process optimizations Figure 3. All Falcon concentrates were combined and mixed to produce a feed sample for the intensive cyanide leach experiments. The leaching of concentrate was conducted for 24 hours at high cyanide concentrations $(20 \mathrm{~g} / \mathrm{L})$ at $\mathrm{pH} 10.5$, ambient temperature, $25 \%$ solid, and $\mathrm{PbNO}_{3}$ at concentration of $98.2 \mathrm{~g} / \mathrm{t}$.

The main reason of adding lead is to reactivated and catalyst the gold surface and oxides any Sulphur formed on the gold surface $[15,16])$. This action inhibits the formation of thiocyanate via thiosulphate and polythionate species, and inhibits the passivation of gold by Sulphur films. Similarly, the tails from Falcon were also combined to form a composite tails for cyanidation (48 hours with $1 \mathrm{~g} / \mathrm{L}$ $\mathrm{NaCN}$ ). Each test was carried out with and without lead nitrate, added at approximately $100 \mathrm{~g} / \mathrm{t}$, for four experiments[17].

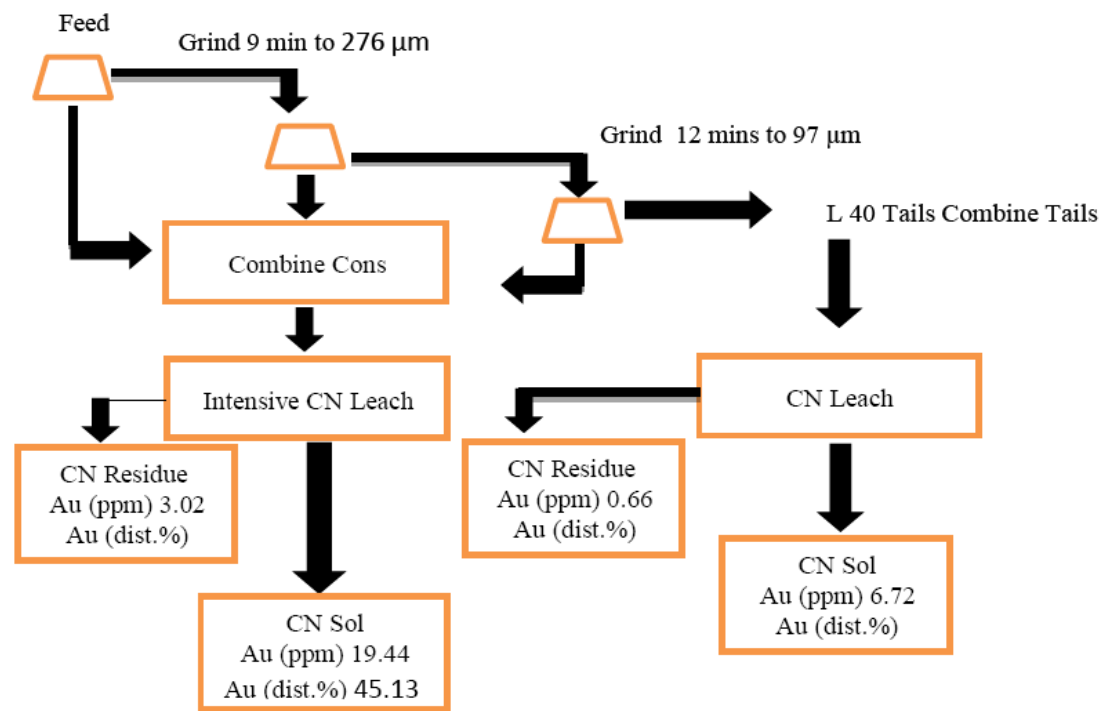

Figure3. Falcon HMY and CN combined Flow sheet [7] 


\section{Dr. Gamal Saad Abelhaffez}

The cyanidation of the different gravity tails and concentrates are presented in Table 5. The cyanidation results from concentrate leaching showed that gold recovery of $96.5 \%$ can be achieved indicated a free milling prospective of the Bir-Taweelah deposit[7].

Table5. Cyanidation of Gravity tails (A-tails and B-concentrate)

(A)

\begin{tabular}{|c|c|c|c|c|c|c|c|}
\hline Sample & Test & $\begin{array}{l}\text { Leach } \\
\text { Time (hr) }\end{array}$ & $\begin{array}{l}\text { Lead } \\
\text { Nitrate }\end{array}$ & $\begin{array}{c}\text { Cal Head } \\
(\mathrm{g} / \mathrm{t})\end{array}$ & $\begin{array}{c}\text { Residue } \\
(\mathrm{g} / \mathrm{t})\end{array}$ & $\begin{array}{c}\text { Au Rec. } \\
(\%)\end{array}$ & $\begin{array}{c}\text { CN Consp } \\
(\mathrm{kg} / \mathrm{t})\end{array}$ \\
\hline BTHG & KP121 & 48 & No & 2.91 & 0.68 & 76.6 & 0.59 \\
\hline BTHG & KP122 & 48 & Yes & 2.94 & 0.67 & 77.2 & $0.57^{*}$ \\
\hline BTHG & KP125 & 48 & Yes & 2.94 & 0.63 & 78.7 & 0.05 \\
\hline BTHG & KP125B & 48 & Yes & 2.67 & 0.66 & 75.4 & 0.10 \\
\hline
\end{tabular}

(B)

\begin{tabular}{|c|c|c|c|c|c|c|c|}
\hline Sample & Test & $\begin{array}{c}\text { Leach } \\
\text { Time }(\mathrm{hr})\end{array}$ & $\begin{array}{l}\text { Lead } \\
\text { Nitrate }\end{array}$ & $\begin{array}{c}\text { Cal Head } \\
(\mathrm{g} / \mathrm{t})\end{array}$ & $\begin{array}{c}\text { Residue } \\
(\mathrm{g} / \mathrm{t})\end{array}$ & $\begin{array}{c}\text { Au Rec. } \\
(\%)\end{array}$ & $\begin{array}{c}\text { CN Consp } \\
(\mathrm{kg} / \mathrm{t})\end{array}$ \\
\hline BTHG & KP123 & 24 & No & 81.47 & 3.17 & 96.1 & 1.42 \\
\hline BTHG & KP124 & 24 & Yes & 82.57 & 2.88 & 96.5 & 0.45 \\
\hline
\end{tabular}

\section{Circuit Modeling}

The results from the cyanidation tests were incorporated into a gravity balance to determine the gold distribution as shown in Figure 4.

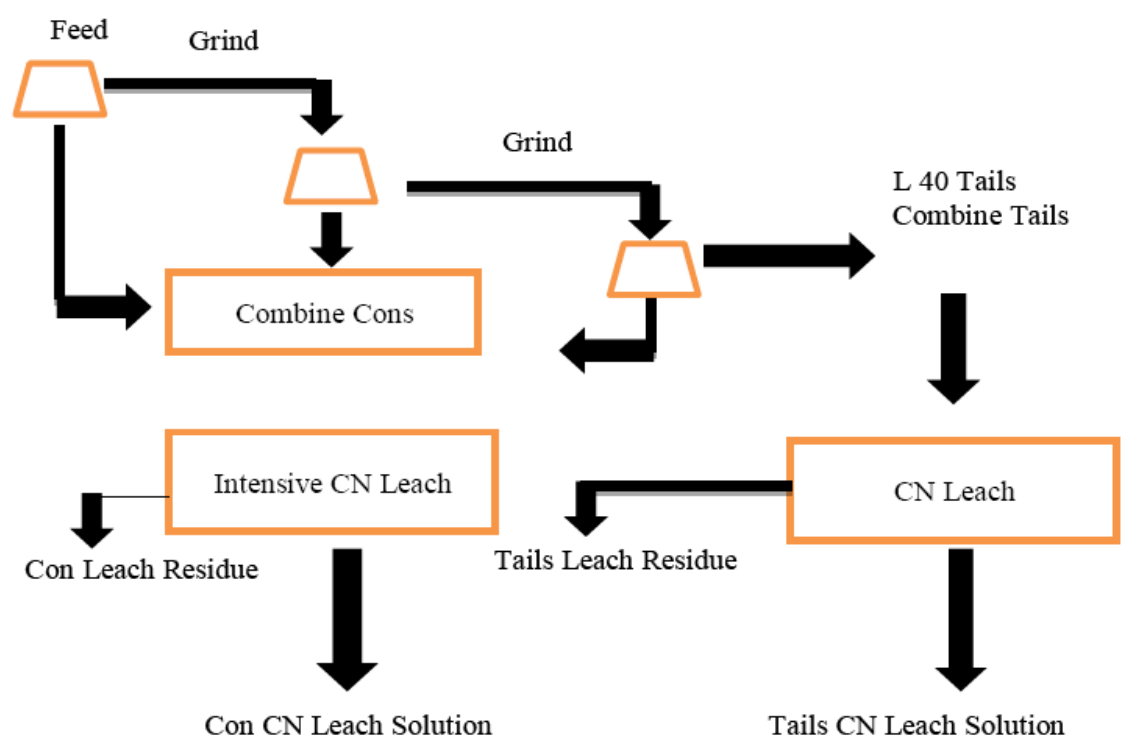

Figure4. Flow sheet gravity + cyanidation for Bir-Taweelah [14]

The combined recovery of the flow sheet is depicted at Table 5 .

Table5. Combined results of flowsheet.

\begin{tabular}{|c|c|c|c|c|c|c|c|}
\hline \multirow[t]{2}{*}{ Sample } & \multirow{2}{*}{$\begin{array}{l}\text { Avg Head } \\
\text { (g/t Gold) }\end{array}$} & \multicolumn{3}{|c|}{ CN Solution (Au Distribution\%) } & \multicolumn{3}{|c|}{ Residue (Au Distribution\%) } \\
\hline & & Con Leach & Tail Leach & Total & Con Leach & Tail Leach & Total \\
\hline BTHG & 6.15 & 45.1 & 40.9 & 86.0 & 1.7 & 12.2 & 13.9 \\
\hline
\end{tabular}

An average gold recovery of $82.5 \%$ was achieved by the application of gravity recovery and cyanide leaching. The gold recovery can be improved by adding another leaching stage on the tails. 


\section{Conclusions}

The results of this research study indicate that the amenability of Bir-Tawellah gold deposit for gravity separation with an acceptable gold recovery. The cyanidation results from concentrate leaching showed that gold recovery of $96.5 \%$ can be achieved. Gravity circuit modeling indicated an average gold recovery of $82.5 \%$ was achieved by the application of gravity recovery and cyanide leaching. The gold recovery can be improved by adding another leaching stage on the gravity tails. The CN consumption indicates that the presence of base metals and cyanide consumable gangue materials are at minimum and should not affect the cyanidation process. The results from gravity recovery and cyanidation showed that the deposit could be ranked as free milling with no gold Telluride present.

\section{REFERENCES}

[1] Laplante, A.R., "Gravity Recovery of gold -An overview of recent developments", McGill University Department of Mining, Metals and Materials Engineering 3610, University Street, Wong Building Montréal, Québec, Canada H3A2B2, (2005).

[2] Andre McKen, Steve Williams, "An Overview of the Small-scale Tests Available to Characterize Ore Grindability for Design Purposes", SGS TECHNICAL BULLETIN, (2005).

[3] Gasparrini, C.: The mineralogy of gold and its significance in metal extraction. CIM Bulletin, Vol. 76, No.851, (1983), pp. 144- 153,.

[4] Hong, J., Wang, K. \& Zhou, Y.: Mineralogy and occurrence of gold in the Larima Carlin- type deposit, Sichuan, China. Chronique de Ia Recherdue Miniere, No. 538, (2000), pp. 17-23,.

[5] Joe Zhou, Bruce Jago and Chris Martin ,. "SGS Lakefield Research Limited SGS MINERALS TECHNICAL BULLETIN" (2004),-03.

[6] Young, C. A. and Jordan, T.S., "Cyanide Remediation: Current and Future Past Technologies", Department of Metallurgical, Montana Tech. Butte, MT 59701, Proceedings of the 10th Annual Conference on Hazardous Waste Research, (1995).

[7] McNulty, T. "Alternatives to cyanide for processing precious metal ores", Mining Environmental Management: The Cyanide Guide, May (2001), pp 35-37.

[8] Adel A Surour., Rami, A. Bakhsh. and Said A El-Nisr "Ore microscopic characterization of mineralized rocks at the Bi'r Tawilah gold prospect, Saudi Arabia", Journal of Microscopy and Ultrastructure, Volume 2, Issue 1, March (2014), pp 41-55

[9] Adel A. Surour, Hesham M. Harbi, and Ahmed H. Ahme, "The Bi'r Tawilah deposit, central western Saudi Arabia: Supergeneenrichment of a Pan-African epithermal gold mineralization", Journal of African Earth Sciences, Volume 89, January (2014), pp 149-163.

[10] Al Jahdli, N.S., "Geology of Jabal Ghadarah Area, Bi'r Tawilah District with Special Emphasis on Listvinite as a Potential Source for Gold in the Kingdom of Saudi Arabia". M.Sc. Thesis, King Abdulaziz University, Jeddah, Saudi Arabia, (2004).

[11] Wan, R.Y., "Importance of metallurgical research on refractory gold processing". Mining Engineering, SME, November, (2001), pp 41-46.

[12] Bujalski, J., Tiller-Jeffery, R., Watling, H. and Schwarz, M.P., "CFD modeling and comparison with experimental residence time distributions in single and two-phase porous flow", 3rd International Conference on CFD in the Minerals and Process Industries, CSIRO Melbourne Australia, 10-12 December, (2003), pp 463-468.

[13] Leahy, M.J., Davidson, M.R. and Schwarz, M.P., "A two-dimensional CFD model for heap bioleaching of chalcocite", ANZIAM J. 46 (2005), pp 439-457.

[14] Met-Solve Laboratories Inc. Canada, "Metallurgical samples testing for CAGR- Bir-Tawellah deposit" Report MS1345, (2011).

[15] Hollow, J. T., Hill, E.M., Lin, H.K., Walsh, D.E.,"The effect of $\mathrm{Pb}(\mathrm{NO} 3) 2$ addition on the processing of blended Fort Knox and True North ores at the Fort Knox mine, Alaska. " Minerals and Metallurgical Processing 20(4), (2003), pp185-190.

[16] Jeffrey, M.I., Ritchie, I.M., La Brooy, S.R.. "The Effect of Lead on the Electrochemistry of Gold:-Myth or Magic." Electrochemist Processing 6(96), (1996), pp 284-295.

[17] Parga, J.R., Valenzuela, J.L \& Cepeda, F.. "Pressure cyanide leaching for precious metals recovery". Journal of Metals, 10, (2007), pp,43-47. 